Assiut Scientific Nursing Journal

http://asnj.journals.ekb.eg

http://www.arabimpactfactor.com

\title{
Nurse's Knowledge about Maternal Near Miss Cases at Woman's Health Hospital, Assiut University.
}

\author{
Magda Ahmed Farahat ${ }^{1}$, Manal Farouk Mostafa ${ }^{2}$, Entisar Mohamed Younes ${ }^{3}$ \& Ahmed Mohamed Abbas ${ }^{4}$. \\ 1. Assistant lecturer, Faculty of Nursing, Assiut University, Egypt. \\ 2. 3 professor of obstetrics \& gynecological nursing, Faculty of Nursing, Assiut University, Egypt. \\ 4. Assistant professor of obstetrics \& gynecology, Faculty of medicine, Assiut University, Egypt.
}

\begin{abstract}
Background: Maternal morbidity and mortality remain unacceptably high in developing countries. Behind every maternal death, a lot of women suffered from acute and chronic obstetric complications. Women who survive severe acute maternal morbidities/near miss have many characteristics in common with maternal death events particularly on risk factors. The aim: Was to assess nurse's knowledge about maternal near-miss cases at Woman's Health Hospital, Assiut University. Subjects and methods: This study was conducted at Woman's Health Hospital, Assiut University from June to November 2019, A descriptive cross-sectional study and a convenience sample of 146 nurses (126 diploma nurses and 20 baccalaureate nurse) was used. A self-administered structured questionnaire for nurses regarding maternal near-miss was used to collect the data.

Results: The majority of nurses showed an inadequate level of knowledge about maternal near-miss cases in most of the items like (definition \& causes of maternal near-miss, symptoms \& management of shocking cases, their knowledge about postpartum hemorrhage, preeclampsia, pulmonary embolism as principal causes of maternal near miss) Conclusion: It was concluded that the knowledge of nurses on maternal near-miss cases was inadequate. Recommendations: Results suggests an urgent need for education and awareness programs for improvement in nurse's knowledge regarding maternal near-miss cases.
\end{abstract}

\section{Keywords: Knowledge, Maternal Near-Miss cases \& Nurses.}

\section{Introduction}

Maternal mortality is a very serious critical event that is continuously used to assess the quality of any health care system. For measuring maternal mortality, there is a standard indicator which is the Maternal Mortality Ratio (MMR is defined as the ratio of the number of maternal deaths per 100,000 live births. The rate of maternal mortality has been decreased globally due to improvements in health care. Maternal mortality (MM) is almost seen as "just the tip of the iceberg" meaning that there is a vast base to the iceberg in the form of maternal near-miss (MNM) i.e. maternal morbidity which has remained largely not described. (UNDP, 2018)

Maternal near-miss is occurring when the woman is showing dangerous complications during pregnancy, childbirth, and within 42 days after delivery, but survived by good health care or by chance. Currently, the quality of obstetric care in low-income countries is measured by the ratio of maternal near-miss cases. (WHO, 2011)

The maternal near-miss has become an important indicator of the quality of obstetric care and the reasons for maternal morbidity because maternal near misses are occurring more frequently than maternal deaths. (Fouly et al., 2018)
Nurses and midwives comprise the greatest proportion of health system workforce globally (Morin and Yan, 2016). They make significant contributions to the delivery of health care in acute and primary heath care settings. As the largest group of health care providers they are the first point of contact for individuals and communities most in need. (Yan, 2016)

The prevalence of maternal near-miss is changeable around the world. A systematic review data of 46 countries showed that the prevalence is varying from 0.04 to $14.98 \%$, with higher rates in the regions which has low income in Africa and Asia. A study done in Holland in 2010, evaluated 358,874 births, showed that there are 2.4 cases of maternal near-miss per 1000 live births. In Brazil, a multicentric study of 27 maternity reference centers, which utilized the criteria of WHO to identify the cases of the maternal nearmiss, registered 3.5 cases per 1000 live births. (Oliveira et. al, 2014)

The new studies showed that the Egyptian maternal near-miss ratio MNMR per 1000 living birth was $12.1 \%$ and maternal near-miss (MNM) mortality was 11:1\%. (Fouly, et Al., 2018)

The Maternal mortality ratio was very high in Women's Health Hospital, Assiut University, Egypt reached 225/100,000, however, the women who delivered in the hospital; the MMR was 
$100.5 / 100,000$. The most important causes of maternal deaths were obstetric hemorrhage (38.3\%), complications of cesarean sections $(27.7 \%)$, and preeclampsia/eclampsia (23.4\%). Also noted that nearly half $(42 \%)$ of the deaths occurred during holidays. Quality indicators reported poor quality of health care.

(Zahran et al., 2017)

Nurses as afrontline health providers play an important role in reducing maternal morbidities and mortalities (Chamberlin, et. al, 2013). Their scientific role is to provide professional services to pregnant women through out the maternity cycle by ensuring a normal pregnancy, safe deivery and anormal peurperium (Thompson, 2011).

Nurses who are practising within the set standards in Essential Obstetric Care (EOC) facilities can effectively reduce maternal mortaity. ( Thompson, 2011).

One of the main interventions to reduce maternal mortality in Egypt is to raise the knowledge of nurses who deal with mothers about its issues especially in rural communities where there are low levels of education and incomes.

\section{Significance of the study}

Maternal death is one of the most destructive implications for the healthcare system, community and family. Five percentages of maternal deaths are occurring in Arab countries and 390,000 women in the Middle East complain from long-life complications due to pregnancy and childbirth. One of the solutions for improving maternal mortality rates in these countries is to understand the causes of maternal mortality then improving in clinical care. (El-Nemer \& Mosbah, 2015)

The obstetric nurse is in an important position for improving maternal outcomes through the recognition, anticipation, and communication of the early warning signs of impending deterioration in maternal condition. The professional nurse can actively influence directly on maternal outcomes, with actions defined by the scope of professional nursing practice or indirectly through professional interactions with others. Advancing nursing education, knowledge, and technical skills broaden the influential capacity. (Witcher et Al., 2015)

In developing countries, about $75 \%$ of women with obstetric complications are already in critical condition when they arrive at tertiary care. Hence the medical staff at the peripheral health centers should be made aware of the danger signals and utilization of maternal near-miss review done. (Patil et Al., 2018) Awareness of nurses about causes of maternal mortality is a very important step as a preventive measure to reduce the rate of maternal mortality and to understand the misconception of nurse's knowledge.
So this study was to assess knowledge of nurses about maternal near-miss issues at woman's health hospital, Assiut University.

\section{Aim of the study}

The aim of the study was to assess nurse's knowledge about maternal near-miss cases at Woman's Health Hospital, Assiut University.

\section{Research questions}

What is the level of nurse's knowledge at Woman's Health Hospital, Assiut University about maternal near-miss?

\section{Subjects and methods}

Research design: A descriptive cross-sectional study was carried out from June to Novembre 2019. A convenience sample of 146 nurses (126 diploma nurse and 20baccalaureate nurse) participated in this study, the data was collected using a self-administered structured questionnaire and it was analyzed using SPSS version 22.0.

The setting of the study: The study was conducted at Woman's Health Hospital, Assiut University; it is an educational university hospital for both public and private hospitals in Assiut and other surroundings in upper Egypt. In addition to providing twenty-fourhour emergency obstetric services, the hospital also provides antenatal care and delivery services for both low and high-risk pregnancies. It also provides emergency obstetric care over $24 \times 7$ days, emergency surgeries, maternal intensive care unit facilities, blood and blood product transfusion, Radiology services, and other specialist services. Around 750 deliveries are conducted per month. This hospital has 7 floors they were: Reception Unit, administrative floor, Postpartum Unit, Emergency Unit, and Maternal ICU, Inpatient 4th, 5th \& 6th floor

Sample: A convenience sample of 146 nurses (126 diploma nurses and 20 baccalaureate nurse) was used. The sample size was calculated using Epi-info statistical package, version 3.3 with power $80 \%$ value of $2.5 \%$, is chosen as the acceptable limit of precision (D) at a $95 \%$ level of confidence (CI), with expected prevalence $50 \%$ and worst acceptable $16 \%$.

Pilot study

A pilot study was carried out before starting data collection on $10 \%$ of nurses (15) in order to test the clarity and applicability of including questions and statement content, feasibility, and consistency of the tool to detect any ambiguity in the study tools. The pilot study also served to estimate the time required to fill the form.there was no modification in the tool and the pilot study was included in the sample.

Inclusion criteria

Nurses who work at woman's health hospital, Assuit University and accept to participate. 
The tool of the study: Data collection was done through the use of the following tool

A total of 146 nurses at Woman's Health Hospital, Assiut University was evaluated with a selfadministered structured questionnaire regarding maternal near-miss which include:

- Part 1: This part was including sociodemographic data of nurses as (place of work, age, educational level, experience, and attending in training programs).

- Part 2: This part was including questions to assess nurse's knowledge about maternal nearmiss such as (definition, high-risk group, incidence, and the most common causes of maternal near miss)

- Part 3: This part was including questions to assess nurse's knowledge about management of maternal near-miss cases such as (initial assessment, danger signs, prevention, and readiness to a near-miss case)

- Part 4: This part was including questions to assess nurse's knowledge about shocking cases. Such as (signs \& management of shock)

- Part 5: This part was including questions to assess nurse's knowledge about preeclampsia and eclampsia such as (management of eclamptic fits, the antidote of magnesium sulfate)

- Part 6: This part was including questions to assess nurse's knowledge about postpartum hemorrhage such as (definition, amount of blood loss, prevention and management)

- Part 7: This part was including questions to assess nurse's knowledge about pulmonary embolisms such as:( definition, most common site, risk factors, signs, and prevention)

\section{Knowledge scoring system}

The number of questions that measure nurse's knowledge about maternal near-miss was 28 so, the subject's response was recorded using 3 point scale. The numerical value allotted to each response is as following: "correct 3, Incorrect 2, Unknown 1. Then the total score was calculated from 100 degrees and classified into an adequate score $(\geq 70 \%)$ and inadequate score $(<70 \%)$.

\section{Validity and Reliability}

The content validity was reviewed by 3 expert opinions in the obstetrics and gynecological nursing field.

\section{Ethical considerations}

1. The research proposal was approved from the Ethical Committee in the Faculty of Nursing

2. There was no risk of study subjects during the application of the research.
3. The study was followed by common ethical principles in clinical research.

4. Oral consent was obtained from each nurse that was willing to participate in the study.

5. Confidentiality and anonymity were assured.

6. Nurse's privacy was considered during the collection of data.

\section{Procedure}

Written approval was taken from the director of Woman's Health Hospital to conduct this study and oral consent was taken from nurses who participated in the study .the purpose and nature of the study was explained for directors and every interviewed nurse. Participant nurses had an ethical right to accept or refuse participation in the study, the information obtained is confidential and used only for the purpose of the study.

- -A review of national and international related literature of the current study using textbooks, articles, and scientific journals was done. Then the tool was prepared based on this literature and it was reviewed for validation by supervisors.

- Data collection was over 6 months from June to November 2019; the number of nurses was 146 dividing in all hospital departments. Every nurse was interviewed in her working place according to a suitable time for her, some nurses were interviewed in the morning shift, others in the afternoon and night. Every nurse was asked to respond on the questions of the self-administered interview questionnaire which was containing 28 questions to assess their knowledge about maternal near-miss, if the nurse respond correctly to more than $70 \%$ (20question) consider her knowledge adequate and if respond correctly to less than $70 \%$ consider her knowledge Inadequate

\section{Statistical design}

Data entry and statistical analysis were done using the statistical package for social science program (SPSS. version 22).qualitative variables were presented as number and percentage. Quantitative variables were presented as mean +SD. Comparsion between qualitative variables was done by using chi-square. Comparsion between quantitative variables was done by using the student t-test. 


\section{Results}

Table (1): Distribution of the studied nurses according to their Sociodemographic characteristics.

\begin{tabular}{|c|c|c|}
\hline Sociodemographic characteristics & Number 146 & Percent \% \\
\hline 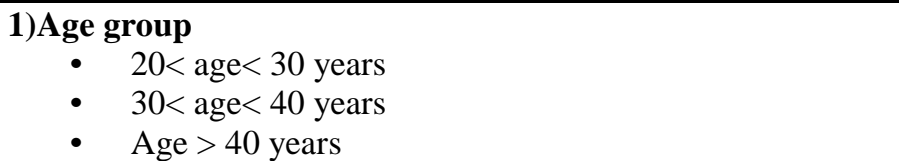 & $\begin{array}{c}98 \\
42 \\
6\end{array}$ & $\begin{array}{c}67.1 \\
28.8 \\
4.1\end{array}$ \\
\hline Mean and SD & \multicolumn{2}{|c|}{$28.77 \pm 6.1$} \\
\hline $\begin{array}{l}\text { 2)Academic qualification } \\
\text { - University education } \\
\text { - Secondary education / technical diploma / technical institute } \\
\text { - Master }\end{array}$ & $\begin{array}{c}16 \\
125 \\
5\end{array}$ & $\begin{array}{c}11.0 \\
85.6 \\
3.4 \\
\end{array}$ \\
\hline $\begin{array}{l}\text { 3)Years of experience in obstetrics and gynecology: } \\
\text { - } \quad \text { Experience }>\mathbf{2} \text { years } \\
\text { - } 2 \leq \text { experience }>5 \text { (years) } \\
\text { - } \quad 5 \leq \text { experience }>\mathbf{1 0} \text { (years) } \\
\text { - } \quad \text { experience }>10\end{array}$ & $\begin{array}{l}23 \\
21 \\
32 \\
70\end{array}$ & $\begin{array}{l}15.8 \\
14.4 \\
21.9 \\
47.9\end{array}$ \\
\hline Mean and SD & \multicolumn{2}{|c|}{$7.49 \pm 4.8$} \\
\hline $\begin{array}{l}\text { 4) attended any specialized training courses } \\
\text { - Yes } \\
\text { - No }\end{array}$ & $\begin{array}{l}71 \\
75\end{array}$ & $\begin{array}{l}48.6 \\
51.4\end{array}$ \\
\hline
\end{tabular}

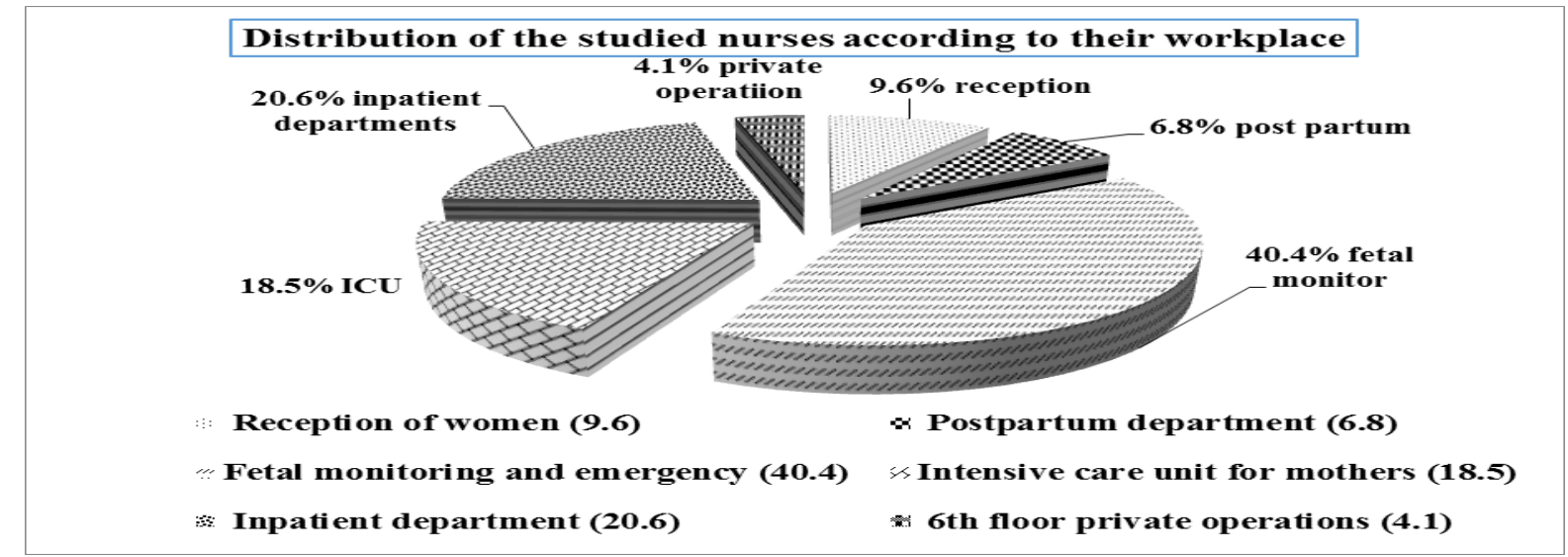

Figure (1): Distribution of the studied nurses according to their work place

Table (2): Distribution of the studied nurses according to their knowledge about the cases of maternal near miss.

\begin{tabular}{|c|c|c|}
\hline Nurse's knowledge about cases of maternal near miss: & Number 146 & Percent \% \\
\hline $\begin{array}{l}\text { 1) Definition of near miss } \\
\text { - Correct answer } \\
\text { - Incorrect answer } \\
\text { - Don't Know }\end{array}$ & $\begin{array}{l}55 \\
76 \\
15\end{array}$ & $\begin{array}{l}37.7 \\
52.1 \\
10.3\end{array}$ \\
\hline $\begin{array}{l}\text { 2) Number of maternal deaths in Women's Health Hospita } \\
\text { according to the latest statistics in } 2017 \\
\text { - Correct answer } \\
\text { - Incorrect answer } \\
\text { - Don't Know }\end{array}$ & $\begin{array}{c}1 \\
38 \\
107\end{array}$ & $\begin{array}{c}0.7 \\
26.0 \\
73.3\end{array}$ \\
\hline $\begin{array}{l}\text { 3) Causes of maternal deaths } \\
\text { - Correct answer } \\
\text { - Incorrect answer } \\
\text { - Don't Know }\end{array}$ & $\begin{array}{c}43 \\
98 \\
5\end{array}$ & $\begin{array}{c}29.5 \\
67.1 \\
3.4\end{array}$ \\
\hline
\end{tabular}




\begin{tabular}{|c|c|c|}
\hline Nurse's knowledge about cases of maternal near miss: & Number 146 & Percent \% \\
\hline $\begin{array}{l}\text { 4) Who are the most vulnerable women to death? } \\
\text { - Correct answer } \\
\text { - Incorrect answer }\end{array}$ & $\begin{array}{l}78 \\
68\end{array}$ & $\begin{array}{l}53.4 \\
46.6\end{array}$ \\
\hline
\end{tabular}

Table (3): Distribution of the studied nurses according to their knowledge about management of maternal near miss cases:

\begin{tabular}{|c|c|c|}
\hline Nurse's knowledge about management of maternal near miss cases: & $\begin{array}{c}\text { Number } \\
146\end{array}$ & $\begin{array}{c}\text { Percent } \\
\%\end{array}$ \\
\hline $\begin{array}{l}\text { 1) A quick initial assessment is made for } \\
\text { - Correct answer } \\
\text { - Incorrect answer }\end{array}$ & $\begin{array}{c}124 \\
22\end{array}$ & $\begin{array}{l}84.9 \\
15.1\end{array}$ \\
\hline $\begin{array}{l}\text { 2) What are the risk signs that need a rapid initial assessment? } \\
\text { - Correct answer } \\
\text { - Incorrect answer }\end{array}$ & $\begin{array}{l}89 \\
57\end{array}$ & $\begin{array}{l}61.0 \\
39.0\end{array}$ \\
\hline $\begin{array}{l}\text { 3) Ways of prevention of maternal mortality } \\
\text { - Correct answer } \\
\text { - Incorrect answer }\end{array}$ & $\begin{array}{c}115 \\
31\end{array}$ & $\begin{array}{l}78.8 \\
21.2\end{array}$ \\
\hline $\begin{array}{l}\text { 4) Prepare for an emergency case } \\
\text { - Correct answer } \\
\text { - Incorrect answer }\end{array}$ & $\begin{array}{c}137 \\
9\end{array}$ & $\begin{array}{c}93.8 \\
6.2\end{array}$ \\
\hline
\end{tabular}

Table (4): Distribution of the studied nurses according to their knowledge about management of shocked cases.

\begin{tabular}{|l|c|c|}
\hline \multicolumn{1}{|c|}{ Nurse's knowledge about management of shocked cases } & Number $\mathbf{1 4 6}$ & Percent \% \\
\hline 1) Symptoms of shock include the following & & \\
- Correct answer & 64 & 43.8 \\
- Incorrect answer & 76 & 52.1 \\
\hline Don't Know & 6 & 4.1 \\
\hline$\quad$ Correct answer & \multicolumn{2}{|}{} \\
- Incorrect answer & 19 & 13.0 \\
- Don't Know & 120 & 82.2 \\
\hline
\end{tabular}

Table (5): Distribution of the studied nurses according to their knowledge about management of preeclampsia cases.

\begin{tabular}{|l|c|c|}
\hline Nurse's knowledge about management of pre-eclampsia cases: & Number $\mathbf{1 4 6}$ & Percent \% \\
\hline $\begin{array}{l}\text { 1)Most important considerations when dealing with the case of } \\
\text { convulsions due to pre-eclampsia are: }\end{array}$ & & \\
Correct answer & 5 & 3.4 \\
Incorrect answer & 141 & 96.6 \\
\hline 2) The antidote of magnesium sulfate; & 12 & \\
Correct answer & 103 & 70.2 \\
In correct answer $\quad$ Don't Know & 31 & 21.2 \\
\hline 3) following should be considered when administering & & \\
magnesium sulfate: & 53 & 36.3 \\
- Correct answer & 79 & 54.1 \\
- In correct answer & 14 & 9.6 \\
\hline
\end{tabular}


Table (6): Distribution of the studied nurses according to their knowledge about management of postpartum hemorrhage cases.

\begin{tabular}{|c|c|c|}
\hline $\begin{array}{l}\text { Nurse's knowledge about management of postpartum } \\
\text { hemorrhage cases: }\end{array}$ & $\begin{array}{c}\text { Number } \\
146\end{array}$ & $\begin{array}{l}\text { Percent } \\
\%\end{array}$ \\
\hline $\begin{array}{l}\text { 1) Definition of postpartum hemorrhage } \\
\text { - Correct answer } \\
\text { - Incorrect answer }\end{array}$ & $\begin{array}{l}61 \\
85\end{array}$ & $\begin{array}{l}41.8 \\
58.2\end{array}$ \\
\hline $\begin{array}{l}\text { 2) How much blood is lost until we consider it } \\
\text { postpartum hemorrhage? } \\
\text { - Correct answer } \\
\text { - In correct answer } \\
\text { - Don't Know }\end{array}$ & $\begin{array}{l}71 \\
71 \\
4 \\
\end{array}$ & $\begin{array}{l}48.6 \\
48.6 \\
2.7\end{array}$ \\
\hline $\begin{array}{l}\text { 3) Which of the following is a sign of postpartum } \\
\text { hemorrhage? } \\
\text { - Correct answer } \\
\text { - In correct answer }\end{array}$ & $\begin{array}{l}80 \\
66\end{array}$ & $\begin{array}{l}54.8 \\
45.2\end{array}$ \\
\hline $\begin{array}{l}\text { 4) The most important important steps to treat } \\
\text { postpartum hemorrhage both of the following? } \\
\text { - Correct answer } \\
\text { - In correct answer }\end{array}$ & $\begin{array}{c}30 \\
116\end{array}$ & $\begin{array}{l}20.5 \\
79.5\end{array}$ \\
\hline $\begin{array}{l}\text { 5) Which of the following are ways to prevent } \\
\text { postpartum hemorrhage? } \\
\text { - Correct answer } \\
\text { - In correct answer }\end{array}$ & $\begin{array}{l}55 \\
91\end{array}$ & $\begin{array}{l}37.7 \\
62.3\end{array}$ \\
\hline
\end{tabular}

Table (7): Distribution of the studied nurses according to their knowledge about management of pulmonary embolism cases.

\begin{tabular}{|c|c|c|}
\hline $\begin{array}{l}\text { Nurse's knowledge about management of pulmonary embolism } \\
\text { cases }\end{array}$ & $\begin{array}{c}\text { Number } \\
146\end{array}$ & $\begin{array}{l}\text { Percent } \\
\%\end{array}$ \\
\hline $\begin{array}{l}\text { 1) Definition of pulmonary embolism: } \\
\text { - Correct answer } \\
\text { - In correct answer } \\
\text { - Don't Know }\end{array}$ & $\begin{array}{c}50 \\
92 \\
4\end{array}$ & $\begin{array}{l}34.2 \\
63.0 \\
2.7\end{array}$ \\
\hline $\begin{array}{l}\text { 2) The most common place where embolism occurs before it } \\
\text { moves into the lung: } \\
\text { - Correct answer } \\
\text { - In correct answer }\end{array}$ & $\begin{array}{l}55 \\
91 \\
\end{array}$ & $\begin{array}{l}37.7 \\
62.3\end{array}$ \\
\hline $\begin{array}{l}\text { 3) Causes and risk factors for pulmonary embolism: } \\
\text { - Correct answer } \\
\text { - In correct answer }\end{array}$ & $\begin{array}{l}72 \\
74\end{array}$ & $\begin{array}{l}49.3 \\
50.7\end{array}$ \\
\hline $\begin{array}{l}\text { 4) The most important symptoms that explain the incidence of } \\
\text { pulmonary embolism of the patient: } \\
\text { - Correct answer } \\
\text { - In correct answer } \\
\text { - Don't Know }\end{array}$ & $\begin{array}{l}46 \\
78 \\
22\end{array}$ & $\begin{array}{l}31.5 \\
53.4 \\
15.1\end{array}$ \\
\hline $\begin{array}{l}\text { 5) All of the following are nursing interventions to prevent the } \\
\text { patient from embolism except: } \\
\text { - Correct answer } \\
\text { - In correct answer } \\
\text { - Don't Know }\end{array}$ & $\begin{array}{c}32 \\
114 \\
0\end{array}$ & $\begin{array}{c}21.9 \\
78.1 \\
0.0\end{array}$ \\
\hline
\end{tabular}


Table (8): Distribution of studied nurses according to their total knowledge about the cases of maternal near miss.

\begin{tabular}{|c|c|c|}
\hline Nurse's total knowledge about the cases of maternal near miss & $\begin{array}{c}\text { Number } \\
\mathbf{1 4 6}\end{array}$ & $\begin{array}{c}\text { Percent } \\
\mathbf{\%}\end{array}$ \\
\hline - Adequate & 65 & 44.5 \\
\hline
\end{tabular}

Table (9): Relationship between total knowledge and Sociodemographic characteristics of studied nurses.

\begin{tabular}{|c|c|c|c|c|c|c|}
\hline \multirow{3}{*}{$\begin{array}{c}\text { Sociodemographic } \\
\text { characteristics of studied nurses: }\end{array}$} & \multicolumn{4}{|c|}{ Total knowledge } & \multirow[t]{3}{*}{ Total } & \multirow[t]{3}{*}{ P-value } \\
\hline & \multicolumn{2}{|c|}{ Adequate } & \multicolumn{2}{|c|}{ In adequate } & & \\
\hline & $\mathbf{N}$ & $\%$ & $\mathbf{N}$ & $\%$ & & \\
\hline 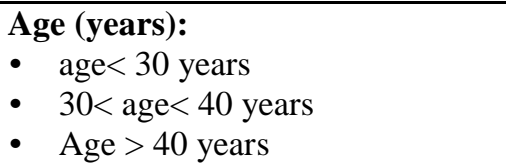 & $\begin{array}{c}23 \\
13 \\
4\end{array}$ & $\begin{array}{l}23.5 \\
31.0 \\
66.7\end{array}$ & $\begin{array}{c}75 \\
29 \\
2\end{array}$ & $\begin{array}{l}76.5 \\
69.0 \\
33.3\end{array}$ & $\begin{array}{c}98(100.0) \\
42(100.0) \\
6(100.0)\end{array}$ & $0.001 * *$ \\
\hline $\begin{array}{l}\text { Academic qualification } \\
\text { - University education } \\
\text { - Secondary education/ technical } \\
\text { diploma/ technical institute } \\
\text { - } \quad \text { Master } \\
\end{array}$ & $\begin{array}{c}7 \\
32 \\
1 \\
\end{array}$ & $\begin{array}{l}43.8 \\
25.6 \\
20.0 \\
\end{array}$ & $\begin{array}{c}9 \\
93 \\
4 \\
\end{array}$ & $\begin{array}{l}56.3 \\
74.4 \\
80.0 \\
\end{array}$ & $\begin{array}{c}16(100.0) \\
125(100.0) \\
5(100.0) \\
\end{array}$ & $0.006 * *$ \\
\hline $\begin{array}{l}\text { Years of experience in obstetrics } \\
\text { and gynecology } \\
\text { - } \quad \text { Experience }<2 \text { years } \\
\text { - } \quad 2 \leq \text { experience }>5 \text { (years) } \\
\text { - } \quad 5 \leq \text { experience }>\mathbf{1 0} \text { (years) } \\
\text { - } \quad \text { Experience }>10 \text { years }\end{array}$ & $\begin{array}{c}6 \\
2 \\
7 \\
25\end{array}$ & $\begin{array}{c}26.1 \\
9.5 \\
21.9 \\
35.7\end{array}$ & $\begin{array}{l}17 \\
19 \\
25 \\
45\end{array}$ & $\begin{array}{l}73.9 \\
90.5 \\
78.1 \\
64.3\end{array}$ & $\begin{array}{l}23(100.0) \\
21(100.0) \\
32(100.0) \\
70(100.0)\end{array}$ & $0.001 * *$ \\
\hline Total & 40 & 27.4 & 106 & 72.6 & $146(100.0)$ & \\
\hline
\end{tabular}

Table (1): shows that $67.1 \%$ of nurses were Less than 30 years, $85.6 \%$ of nurses were Secondary education / technical diploma / technical institute , $47.9 \%$ of them had more than 10 years experience and $51.4 \%$ of them not attended training courses in obstetrics.

Figure (1): Shows that $40.4 \%$ of nurses were working in fetal monitoring and emergency department.

Table (2): Shows that $52.1 \%$ of nurses had incorrect answer about the definition of maternal near miss, $73.3 \%$ of them didn't know it's incidence, $67.1 \%$ of them had incorrect answer about it's causes.

Table (3): Shows that $84.9 \%$ of nurses had the knowledge about for whom the quick initial assessmentis done, $61 \%$ of them knew the risk signs that need a rapid initial assessment, 78.8 knew the ways of prevention, $93.8 \%$ knew the preparatian for an emergency case.

Table (4): Shows that $52.1 \%$ of nurses had incorrect answer about the symptoms of shock, 82.2 of them had incorrect answer about the management of shocked cases.

Table (5): Shows that $96.6 \%$ of nurses had incorrect answer about the most important considerations when dealing with convulsions and $70.5 \%$ respond incorrectly about the antidote of magnesium sulfate.

Table (6): Shows that $58.2 \%$ of nurses had incorrect answer about postpartum haemorrhage definition, $79.5 \%$ respond incorrectly about management of PPH and $62.3 \%$ respond incorrectly about its prevention.

Table (7): Shows that $63 \%$ of nurses had incorrect answer about the definition of pulmonary embolism, $62.3 \%$ respond incorrectly about its common site, more than $50 \%$ had incorrect answer about the risk factors and symptoms and $78.1 \%$ respond incorrectly about ways of prevention.

Table (8): shows that $55.5 \%$ of nurses had inadequate level of knowledge about the cases of maternal near miss.

Table (9): Shows that there was highly highly significance between tatal knowledge of studied nurses and their age, academic qualification and their years of experience ( $\mathrm{p}$-value : 0.001, 0.006, 0.001) respectively

\section{Discussion}

Near-miss cases have similar characteristics with maternal deaths and can tell us the root causes of acute complications. Accordingly, they provide valuable information on obstetric care allowing for 
reformative action to be taken on identified delays to reduce the related mortality and morbidity.

One of the main interventions to reduce maternal mortality in Egypt is to raise the awareness of maternity nurses as aprimary health providers about its issues. So the aim of the present study was to assess the knowedge of nurses about maternal near miss cases at woman's health hospital, Assiut University.

The most important finding to arise from this study was the inadequate level of nurse's knowledge about the maternal near miss. This result is consistent with other studies like (Abd-Elgany et al., 2019) that assessed nurse's knowledge about preventive and therapeutic measures of postpartum hemorrhage in Assiut, Egypt and found that most of nurses had unsatisfactory level of knowledge. Also (Murphy et al., 2019) who studied nursing knowledge of essential maternal and newborn care in a high-mortality urban African setting and found that most of maternity patients are being cared for in an environment where nursing knowledge is very low (score $<0.6$ ). This may be because nurses not receive adequate courses for maternal near miss in their preservice education. This highlights the importance of educating nurses about all maternal health issues for reducing maternal mortality.

As regards to nurse's knowledge about the definition of maternal near-miss more than one-half of nurses had an incorrect answer about it, this result is in agreement with ( Kulkarni, et al., 2019) who studied the impact of training on awareness and knowledge of service providers about maternal near-miss events in Maharashtra, India, their study was done on 147 participants to improve their knowledge level about the maternal near-miss and found that there is lack of knowledge about the definition. Also, these results are in disagreement with (Soggiu-Duta et al., 2019) that studied the impact of an intensive educational program regarding preeclampsia on health professional knowledge and found that their knowledge about the definition and pathophysiology was satisfactory.

As regards nurse's knowledge about the causes of the maternal near-miss, our study showed that more than two-thirds of nurses didn't know the correct answer. This result is in agreement with Martin (2017) whose study surveyed 372 postpartum nurses nationwide and found that Only 24 percent correctly identified the leading causes of maternal death in the U.S such as heart-related problems and in disagreement with Kulkarni., et al., (2019) who found that there was no significant improvement in the level of knowledge about the causes for MNM and maternal deaths, there was a $6 \%$ increase in post-test responses as compared to the pretest responses. In addition, the level of knowledge in the pretest responses was quite high $(81 \%)$

This might be related to the fact that most nurses hold a nursing diploma and a lot of nursing books are written in English and they are learning in Arabic. Also, nearly all of them didn't receive any previous training about the maternal near miss.

As regards nurse's knowledge about management of maternal near-miss cases in the quick initial assessment, risky signs, prevention, and preparing for an emergency case, nurses were quite knowledgable at this point. This is in disagreement with Martin (2017) who was surveyed 372 postpartum nurses nationwide and found that a lot of them had lack of knowledge about the dangers which mothers face after delivery and needing for more education themselves, they were unable to teach mothers about symptoms like painful swelling, headache, heavy bleeding and breathing problems that could indicate potentially life-threatening complications.

As regards the management of shock as a principal leading cause of maternal near-miss, few nurses had the correct answer about how to deal with shocking cases while the majority of them had the incorrect answer. This result is in agreement with Abdelhakm \& Said (2017) who studied developing nursing management protocol for maternity nurses regarding emergency obstetric care and found that only one quarter of nurses had the correct answer in pretest but the vast majority of them had the knowedge in the posttest.

Lack of knowledge may be due to the fact that nurses did not receive adequate information about maternal near miss or maybe in need of refreshment in-services training.

Regarding nurse's knowledge about management of pre-eclampsia cases as a major cause of maternal near-miss, the current study found that there was an inadequate level of their knowledge, this result is in agreement with (Mousa et al., 2013) who studied Updating Nurses' knowledge about Preeclamptic Patients' Care by Using a Poster in Minia Maternal and Child University Hospital and found that the majority of nurses had an incorrect and incomplete answer.

Also, these results are in disagreement with (SoggiuDuta et al., 2019) who study the impact of an intensive educational program regarding preeclampsia on health professional knowledge and found that the scores for the pathophysiology and definition of preeclampsia topics weren't statistically significant $(p>0.05)$ between the pretest and posttest.

These finding of the nurse's knowledge may be attributed to lack of nurse's awareness about the importance of their knowledge as a source of mother's knowledge 
As regards to management and prevention of postpartum hemorrhage there was an inadequate level of nurse's knowledge this is in agreement with (AbdElgany et al., 2019) who studied assessment of nurse's knowledge about preventive and therapeutic measures of postpartum hemorrhage in Assiut, Egypt and found that there was lack of nurse's knowledge of PPH causes, treatment, and prevention in woman's health hospital and in disagreement with (Mutunga, 2015) who studied competence of midwives in prevention and management of postpartum hemorrhage at Kiambu District Hospital labour ward and found that the majority of registered nurses and registered midwives (RN/RM) were found to demonstrate a high level of knowledge in the management of PPH.

As regards to nurse's knowledge about pulmonary embolism as a principal cause of maternal near-miss, nurse's knowledge was inadequate in all items such as definition, causes, risk factors, most common places, and symptoms, these results were in agreement with (Abdul Nasser et al., 2020) who studied the effect of an educational program on critical care nurses performance regarding emergency care for patients with pulmonary embolism and showed that the majority of nurses mean score in preimplementation of the program less than those of the post-implementation. This might be due to the absence of a training program, booklet, and standard for care inside each unit during the period of program implementation.

Our study found that there was highly significance between total knowledge of studied nurses and their age, academic qualification and their years of experience, these results agree with (Azhar \& Ezedeen, 2019) who studied the effectiveness of an educational program on nurse-midwives practices related to postpartum hemorrhage at delivery room of maternity hospitals in Baghdad city and found a relationship between nurse's knowledge, education and experience.

\section{Study strengths \& limitations}

\section{Strengths}

Assessment of nurse's knowledge about maternal near-miss gives us an impression about their educational needs so an educational program is recommended to be done.

\section{Limitations}

The small sample size of the included nurses.

\section{Conclusion}

Based on the findings of this study, it can be concluded that level of nurse's knowledge at Woman's Health Hospital, Assiut University about maternal near-miss was inadequate.
Recommendations : It was recommended to

1- An educational program should be done to increase the nurse's knowledge about the maternal near miss.

2- Encourage nurses to attend educational courses in the form of workshops, conferences, training programs, and review update nursing care related to a maternal near miss.

3- Establish a library with recent scientific books and magazines in an Arabic language and budget should be allowed every year for the educational activities of nurses.

4- Guide posters or pictures about nursing management of maternal near-miss should be placed at the workplace.

\section{References}

1. Abd-Elgany L., Zahran K., \& Ahmed N., \& Abd-Elhafez H., (2019): Assessment of Nurses Knowledge About Preventive and Therapeutic Measures of Postpartum Hemorrhage, Assiut Scientific Nursing Journal, Vol , (7) No, (18)

2. Abdelhakm E., \& Said A., (2017): Developing nursing management protocol for maternity nurses regarding emergency obstetric care, American Journal of Nursing Science 2017; 6 (5): 418-425

3. Abdul Nasser A., Haza A., Faker A., AbdelAziz M., (2020): Effect of An Educational Program on Critical Care Nurses Performance regarding Emergency Care for Patients with Pulmonary Embolism Assiut Scientific Nursing Journal Vol , (8) No, (20, pp (31-44)

4. Azhar H., \& Ezedeen B., (2019): Effectiveness of an education program on nurse-midwives practices related to postpartum hemorrhage at delivery room of maternity hospitals in Baghdad city, Indian Journal of Public Health Research \& Development Volume 10 Issue 9, P 892:896

5. Chamberlin, L., Mcdonagh, S., Lolonde A., (2013): Role of midwives in maternity care. International Journal of Gynaecology and obstetrics. (36):9-15.

6. El-Nemer A., \& Mosbah A., (2015): Maternal Near-Misses in a University Hospital, OSR Journal of Nursing and Health Science (IOSR-JNHS), Volume 4, Issue 3 Ver. $\mathrm{V}, \mathrm{PP} 48-53$

7. Fouly H., Abdou F., \&Abbas A., (2018): Audit for quality of care and fate of maternal critical cases at Women's Health Hospital, Applied Nursing Research V 39, 175-181

8. Kulkarni R., Chauhan S., Patil A., Shivkumar P., Tayade S., Dohate N., (2019): 
Impact of Training on Awareness and Knowledge of Service Providers about maternal near-miss events in Maharashtra, India, The Journal of Obstetrics and Gynecology of India 69(6):529-534

9. Martin N., (2017): Many nurses lack knowledge of health risks to mothers after childbirth, The American Journal of Maternal/Child Nursing.

10. Morin, K., Yan, J., (2016): Developing global standards for initial nursing and midwifery education. Journal of obstetrics, Gynecology and neonatal nursing 136(3):201202

11. Mousa O., Ali H., El Adawy A., (2013): Updating Nurses' knowledge about Preeclamptic Patients' Care by Using a Poster in Minia Maternal and Child University Hospital. J Am Sci , 9(4):658-663

12. Murphy G., Gathara D., Mwaniki A., (2019): Nursing knowledge of essential maternal and newborn care in a high-mortality urban African setting: A cross sectional study. J Clin Nurs. 28:882-893.

13. Mutunga, E., (2015): Competence of Midwives in Prevention and Management of Post partum Haemorrhage at Kiambu District Hospital Labour Ward, Kiambu County.

14. Oliveira F., Surita F., Pinto E., Silva J., Cecatti J., Parpinelli M., Haddad S., Costa M., Pacagnella R., Sousa M., \& Souza J., (2014): Brazilian Network for Surveillance of Severe Maternal Morbidity Study Group, severe maternal morbidity and maternal nearmiss in the extremes of reproductive age: results from a national cross-sectional multicenter study, BMC Pregnancy Childbirth 20; $14: 77$

15. Patil V., Kamath V., \& Rathnamala M., (2018): Obstetric near-miss events and maternal deaths in a tertiary care hospital, Int J Reprod Contracept Obstet Gynecol. 7(2):519523

16. Soggiu-Duta C., Crauciuc D., \& Dmour A., (2019): The Impact of an intensive educational program regarding preeclampsia on health professional

knowledge, REV.CHIM.(Bucharest) 70No.6.

17. United Nation Development Program (2018): support to the implementation of the sustainable development goals

18. WHO (2011): Evaluating the Quality of Care for Severe Pregnancy Complications: The WHO Near Miss Approach for Maternal Health. World Health Organization.
19. Witcher, Patricia M., Sisson \& Melissa C., (2015): Maternal Morbidity and Mortality: Identifying Opportunities to Improve Clinical Outcomes, Journal of Perinatal \& Neonatal Nursing: Volume 29 - Issue 3 - p 202-212

20. Yan J., (2016): Lack of informations threatens patient safetyHIFA. Press release.

21. Zahran K., Fadel K., Ahmed S., \& ElGazzar A., (2017): Maternal mortality in an academic institution in Upper Egypt, Journal of obstetrics and gynecology S37(3):315-319 